\title{
Kinetics of cation adsorption on charged soil mineral as strong electrostatic force presence or absence
}

\author{
Rui Li • Hang Li • Hualin Zhu $\cdot$ Laosheng Wu
}

Received: 17 May 2010 / Accepted: 9 August 2010 /Published online: 28 August 2010

(C) The Author(s) 2010. This article is published with open access at Springerlink.com

\begin{abstract}
Purpose The purposes of this research were to: (1) establish new analytical kinetic equation for describing the effect of strong electrostatic force on adsorption; (2) experimentally determine if it is a strong or weak electrostatic force adsorption process; and (3) evaluate the adsorption energies of the strong and weak force adsorptions based on the proposed new theory of cation adsorption kinetics.

Materials and methods The constantly charged materialmontmorillonite was used in the experiment. The montmorillonite was saturated with two Cation species: $\mathrm{K}^{+}$and $\mathrm{Ca}^{2}$ ${ }^{+}$, respectively, using $\mathrm{KNO}_{3}$ or $\mathrm{Ca}\left(\mathrm{NO}_{3}\right)_{2}$ before it was used for the experiment. The miscible displacement technique under a steady flow condition was adopted to the kinetic studies of $\mathrm{Mg}^{2+}\left(\mathrm{Mg}\left(\mathrm{NO}_{3}\right)_{2}\right)$ adsorption. In the experiment, $0.5000 \mathrm{~g}$ of $\mathrm{K}^{+}$- or $\mathrm{Ca}^{2+}$-saturated montmorillonite was layered on the exchange column, the thickness of sample layer was approximately $0.2-0.3 \mathrm{~mm}$, the cross-sectional area of the column (sample area) was $15 \mathrm{~cm}^{2}$. The concentration of $\mathrm{Mg}^{2+}$ in the flowing liquid was $10^{-4} \mathrm{~mol}$ $\mathrm{L}^{-1}$. The flow velocity of the flowing liquid was $1.0 \mathrm{~mL} \cdot \mathrm{min}^{-1}$. Effluent was collected at 10 -min intervals. Results and discussion Firstly, new and exact rate models for describing ion adsorption have been advanced. Second-
\end{abstract}

Responsible editor: Huijun Zhao

R. Li $\cdot$ H. Li $(\bowtie) \cdot H$. Zhu

College of Resources and Environment,

Southwest Agricultural University,

Chongqing 400716, People's Republic of China

e-mail: hli22002@yahoo.com.cn

L. Wu

Department of Environmental Sciences, University of California, Riverside, CA 92501, USA ly, based on the experiments of $\mathrm{Mg}^{2+} / \mathrm{K}^{+}$and $\mathrm{Mg}^{2+} / \mathrm{Ca}^{2+}$ exchange in $\mathrm{K}^{+}$and $\mathrm{Ca}^{2+}$-saturated montmorillonites, $\mathrm{Mg}^{2+}$ adsorption in $\mathrm{K}^{+}$-saturated sample appeared zero-order kinetic process in the initial stage of the strong force adsorption for $t=0-405 \mathrm{~min}$, and then the adsorption process converted to the first-order kinetics of the weak force adsorption, which agrees with the theoretical prediction. However, for the $\mathrm{Ca}^{2+}$-saturated sample, merely firstorder kinetic process appeared for $\mathrm{Mg}^{2+}$ adsorption. Either for $\mathrm{Mg}^{2+} / \mathrm{K}^{+}$exchange or $\mathrm{Mg}^{2+} / \mathrm{Ca}^{2+}$ exchange, the quantities of $\mathrm{Mg}^{2+}$ by weak force adsorption at equilibrium were almost the same. Thirdly, several important dynamic and thermodynamic parameters can be theoretically calculated based on the new theory in describing cation adsorption.

Conclusions For $\mathrm{Mg}^{2+} / \mathrm{K}^{+}$exchange, both strong and weak electrostatic force adsorptions exist, but for $\mathrm{Mg}^{2+} / \mathrm{Ca}^{2+}$ exchange only the weak electrostatic force adsorption occurs. The strong and weak force adsorption processes can be quantitatively described by the new analytical kinetic equations of the zero- and the first-order kinetics, respectively. Because each parameter in the analytical kinetic equations has its definitive physical meaning, several important dynamic and thermodynamic parameters in cation exchange can be theoretically estimated.

Keywords Cation adsorption . Charged soil . Diffusion layer (DL) - Strong electrostatic force .

Weak electrostatic force

\section{Introduction}

The negative charges on soil particle surface, together with counter-ions in diffuse layer (DL), form an electrostatic 
field in the soil solution adjacent soil particle surface. Recently, $\mathrm{Li}$ and $\mathrm{Wu}$ (2007); Li et al. (2010); Li and Li (2010) found that, cation exchange is essentially a cation diffusion process in the electrostatic field of DL. Li et al. (2010); Li and Li (2010) also found that, the electrostatic field in the DL can substantially speed up the cation diffusion or adsorption process. Besides, experimental results revealed that, when the soil samples were $\mathrm{Ca}^{2+}$ saturated, only the first-order kinetic process was observed for $\mathrm{Mg}^{2+}$ adsorption in the $\mathrm{Mg}^{2+} / \mathrm{Ca}^{2+}$ exchange experiment ( $\mathrm{Li}$ et al. 2010). In contrast, as soil samples were $\mathrm{K}^{+}$saturated, both zero- and first-order kinetic processes appeared for $\mathrm{Mg}^{2+}$ adsorption in $\mathrm{Mg}^{2+} / \mathrm{K}^{+}$exchange experiment ( $\mathrm{Li}$ and $\mathrm{Li}$ 2010). The zero-order kinetic process was considered to be a strong electrostatic force adsorption for $\mathrm{Mg}^{2+}$ ( $\mathrm{Li}$ and $\mathrm{Li}$ 2010). Why did the zero-order process for $\mathrm{Mg}^{2+}$ adsorption appeared in $\mathrm{Mg}^{2+} / \mathrm{K}^{+}$exchange but did not in $\mathrm{Mg}^{2+} / \mathrm{Ca}^{2+}$ exchange experiment, and how could we experimentally distinguish those two states of cation adsorptions?
This research is to develop new kinetic equations by considering the strength of the electrostatic force from the charged particle surface, to determine if the adsorption is caused by the strong or weak electrostatic force in one experiment, and to evaluate the adsorption energies of the strong and weak adsorptions based on the new theory of cation adsorption kinetics.

\section{Theory}

2.1 The flux equations for ion adsorption by considering the electric field from surface charges

In the experiment of the miscible displacement, the adsorption process can be illustrated in Fig. 1. Under this experimental condition, $\mathrm{Li}$ et al. (2010) demonstrated that, in the domain of $x=0 \sim l$, the ionic dynamic distribution can be described by the following equation:

$f_{i}(x, t)=f_{i 0} e^{-\frac{Z_{i} F \varphi(x, t)}{R T}}\left\{1-\sum_{n=0}^{\infty} \frac{4}{(2 n+1) \pi} e^{-\frac{\pi^{2} D_{D_{i}}}{42^{2}}(2 n+1)^{2} t} \sin \left[\frac{(l-x)}{l}(2 n+1) \frac{\pi}{2}\right]\right\}$

where $f_{i}(x, t)$ is the concentration of $i$ th ion species at the distance $x$ away from particle surface and time $t ; \varphi(x, t)$ is the electric potential in the electric field of $\mathrm{DL} ; Z_{i}$ is the charges of the ion species; $F$ is the Faraday constant; $R$ is the gas constant; $T$ is the absolute temperature; $D_{\mathrm{pi}}$ is the apparent diffusion coefficient of ion $i$ th species in soil, and for soil $D_{p i}=\theta\left(l / l_{e}\right)^{2} D_{i} r$ (Kemper and Van Schaik 1966), $\theta$ is the volumetric water content, $\left(l / l_{e}\right)^{2}$ is the tortuosity factor, $D_{i}$ is the diffusion coefficient of the ion; and $r$ is a coefficient accounting for ionic interaction.

Because the series in Eq. 1 converges rapidly, at large $t$ (often larger than several $10 \mathrm{~min}$ depending on the value of $\pi^{2} D / 4 l^{2}$ ), only the term $n=0$ needs to be considered, Eq. 1 becomes:

$f_{i}(x, t)=f_{i 0} e^{-\frac{Z_{i} F \varphi(x, t)}{R T}}\left[1-\frac{4}{\pi} e^{-\frac{\pi^{2} D_{p i}}{4 l^{2}} t} \sin \frac{l-x}{l} \frac{\pi}{2}\right]$

For a period of time $t=0 \sim t$, the total quantity of $i$ th cation species diffusion/adsorption through the plane of $x=l$ into the space of $x=0 \sim l$ should be expressed as:

$N_{i}(t)=S \int_{0}^{l} f_{i}(x, t) \mathrm{d} x$

where $N_{i}(t)$ is the total adsorption quantity $(\mathrm{mol} / \mathrm{g})$ from $t=0$ to $t, S$ is the specific surface area of the sample with unit $\mathrm{dm}^{2} \mathrm{~g}^{-1}$.
According to Eqs. 2 and 3, the flux of $i$ th cation species diffusion/adsorption through the plane of $x=l$ into the space $x=0 \sim l$ can be expressed as:

$$
\begin{aligned}
j_{i} & =\frac{d N_{i}(t)}{S d t} \\
& =D_{p i}\left\{\int_{0}^{l} \frac{\pi f_{i 0}}{l^{2}} e^{-\frac{\pi^{2} D}{4 l^{2}} t} e^{-\frac{Z F \varphi(x)}{\mathrm{RT}}} \sin \left[\frac{(l-x)}{l} \frac{\pi}{2}\right] \mathrm{d} x\right\}
\end{aligned}
$$

According to the definition of the apparent concentration or activity by $\mathrm{Li}$ et al. (Li and $\mathrm{Wu}$ 2004, 2007; Li et al. 2010), Eq. 2 is changed to:

$$
\begin{aligned}
A_{i}(x, t) & =f_{i}(x, t) e^{\frac{Z_{i} F \varphi(x, t)}{R T}} \\
& =f_{i 0}\left[1-\frac{4}{\pi} e^{-\frac{\pi^{2} D_{p i}}{4 l^{2}} t} \sin \frac{l-x}{l} \frac{\pi}{2}\right]
\end{aligned}
$$

where $A_{i}(x, t)$ is the apparent concentration or activity of $i$ th ion species at distance $x$ away from particle surface and time $t$.Introducing Eq. 5 into Eq. 4, there is

$j_{i}=\frac{d N_{i}(t)}{S d t}=\frac{\pi^{2} D_{p i}}{4 l}\left\{\frac{1}{l} \int_{0}^{l} e^{-\frac{Z F \varphi(x)}{R T}}\left[f_{i 0}-A_{i}(x, t)\right] \mathrm{d} x\right\}$

Equation 6 is the flux equation for describing ion diffusion/adsorption by considering the electric field from soil particle surface under the miscible displacement experiment. Equation 6 implies that, the electric field is 
Fig. 1 A conceptual diagram of ion adsorption process in the experiment of the miscible displacement

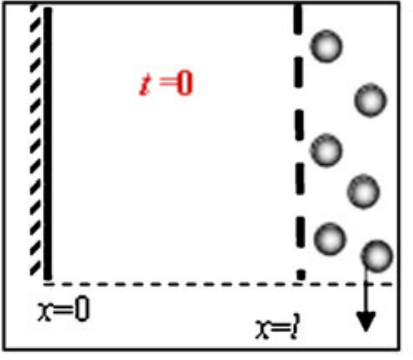

through the average effect of the electric field from $x=0$ to $l$ to influence cation diffusion/adsorption rate or the flux.

\subsection{The adsorption kinetics as strong electrostatic adsorption force presence}

The presence of strong electrostatic adsorption force means a strong negative energy area or a deep potential well near the soil particle surface (as shown in Fig. 2). Once a cation falls into (adsorbed) the strong negative energy area or the potential well, the cation will be strongly adsorbed and thus it will be very difficult to escape from the potential well. Therefore, the strongly adsorbed cation can be treated as "disappeared" immediately from the solution adjacent particle surface. The "disappear" of the absorbed cation means that the activity of the cation in the solution near soil particle surface (in the potential well) is approximately zero. Obviously, this phenomenon will only appear in the initial stage of the cation exchange experiment. This process can be illustrated as in Fig. 2. Mathematically, it can be expressed as:

$f_{i 0}-A_{i}(x, t) \approx f_{i 0}$

Introducing Eq. 7 into Eq. 6, we get the flux equation at the presence of strong adsorption force:

$j_{i}=\frac{d N_{i}(t)}{S d t}=\frac{\pi^{2} D_{p i}}{4 l^{2}} f_{i 0} \int_{0}^{l} e^{-\frac{Z_{i} F \varphi(x)}{R T}} \mathrm{~d} x$

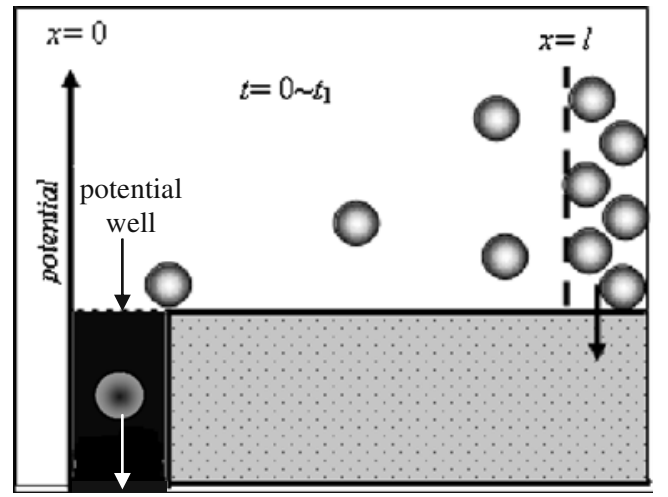

Fig. 2 A conceptual diagram of ion adsorption as strong adsorption presence at particle surface
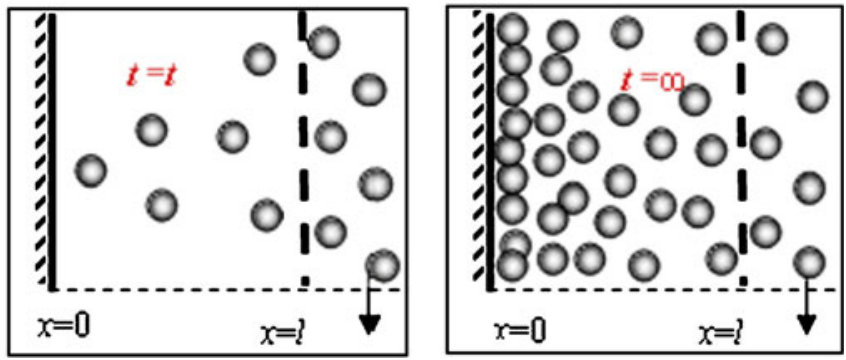

Thus, the rate equation for describing ion adsorption can be expressed as:

$\frac{d N_{i}(t)}{S d t}=k_{1}=k_{1}\left[N_{i}(t)\right]^{0}$

where $k_{1}$ is the rate coefficient, and ( $\mathrm{Li}$ et al. 2010):

$k_{1}=\frac{\pi^{2} D_{p i}}{4 l^{2}} f_{i 0} \int_{0}^{l} e^{-\frac{Z_{i} F \varphi(x)}{R T}} \mathrm{~d} x$

Because Eq. 9 is proportional to the zero power of $N_{i}(t)$, it can be referred as the zero-order rate equation. Thus, the zero-order kinetic process in cation adsorption implies the presence of strong adsorption force.

Li and Xue (1996); Li et al. (2010) suggested an approximate equation for describing zero-order kinetic process, in which the rate coefficient is assumed as:

$k_{1}=\frac{D_{p i}}{l^{2}} f_{i 0} \int_{0}^{l} e^{-\frac{Z_{i} F \varphi(x)}{R T}} \mathrm{~d} x$

which is slightly different from the exact expression of Eq. 10 .

In order to conveniently using the experimental data directly, Eq. 9 can be written to the discrete form:

$\frac{N_{i}\left(t_{m+1}\right)-N_{i}\left(t_{m}\right)}{S\left(t_{m+1}-t_{m}\right)}=k_{1}\left[N_{i}\left(t_{k+1 / 2}\right)\right]^{0}$

where $m=0,1,2,3, \ldots \ldots, N_{i}\left(t_{m+1 / 2}\right)=N_{i}\left(t_{m}\right)+$ $0.5\left[N_{i}\left(t_{m+1}\right)-N_{i}\left(t_{m}\right)\right.$.

Equation 12 implies that, using experimental data obtained in the presence of strong adsorption forces to plot a relationship curve of $\left[N_{i}\left(t_{m+1}\right)-N_{i}\left(t_{m}\right)\right] / S\left(t_{m+1}-t_{m}\right) v s$. $N_{i}\left(t_{m+1 / 2}\right)$, a straight line which is parallel to abscissa axis can be expected, and the intercept of the straight line will be the rate coefficient $k_{1}$ of ion adsorption for the strong force adsorption.

However, when the strong adsorption sites are saturated by the adsorbed cations (strong force adsorption ceased or completed), then the driving force for cation adsorption will shift to the weak electrostatic force, which can be illustrated as Fig. 3.

In the process of weak force adsorption, the distance of ion diffusion is shortened from $0-l$ to $0-l^{\prime}$ as shown in 


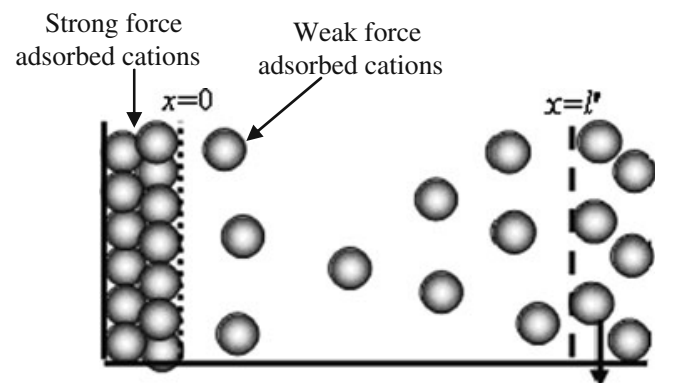

Fig. 3 A conceptual diagram of ion adsorption for the weak force adsorption

Fig. 3, and the rate equation can be expressed as ( $\mathrm{Li}$ et al. 2010):

$\frac{d N_{i}^{\prime}(t)}{S d t}=k_{2}^{\prime}\left[1-\frac{N_{i}^{\prime}(t)}{N_{\infty}^{\prime}}\right]$

where $N_{i}^{\prime}(t)$ is the adsorbed quantity in the second stage for a period of time $t=0 \sim t$ (here $t=0$ means the initial time moment of the weak force adsorption); $N_{\infty}^{\prime}$ is the weak force adsorbed quantity at equilibrium:

$N_{\infty}^{\prime}=S f_{i 0} \int_{0}^{l^{\prime}} e^{-\frac{Z_{i} F \varphi(x)}{R T}} \mathrm{~d} x$

$k_{2}^{\prime}=\frac{\pi^{2} D_{p i}}{4 l^{\prime} 2} f_{i 0} \int_{0}^{l^{\prime}} e^{-\frac{Z_{i} F \varphi(x)}{R T}} \mathrm{~d} x$

Equation 13 shows that ion diffusion/adsorption kinetics in the process of weak force adsorption is a first-order kinetic process.

From the above analysis, the adsorption process can be conceptually described in two stages: zero- and firstorder processes. However, in the second stage (the weak force adsorption), the experimentally determined $N_{i}(t)$ values include the contribution of the adsorbed cation quantities in the first stage, and it is difficult to determine how many cations are strongly adsorbed in advance in the first stage. In order to directly use the experimental data of $N_{i}(t)$ and $N_{\infty}$ to analyze the kinetic characteristics, the upper limit of the integral $l^{\prime}$ in Eqs. 14 or 15 can be replaced by $l$, and correspondingly $t=0$ still means the initial time moment of the strong force adsorption but not the initial time moment of the weak force adsorption. Nevertheless, we should note that in Eq. 15, the $l^{\prime}$ in $\pi^{2} D_{p i} / 4 l^{\prime 2}$ cannot be replaced by $l$ (see the derivation of $k$ in our previous paper ( $\mathrm{Li}$ and $\mathrm{Li} 2010)$ ). Thus the discrete form of Eq. 13 can be expressed as:

$\frac{N_{i}\left(t_{m+1}\right)-N_{i}\left(t_{m}\right)}{S\left(t_{m+1}-t_{m}\right)}=k_{2}-\frac{k_{2}}{N_{\infty}} N_{i}\left(t_{m+1 / 2}\right)$ where $N_{i}\left(t_{m+1 / 2}\right)=N_{i}\left(t_{m}\right)+0.5\left[N_{i}\left(t_{m+1}\right)-N_{i}\left(t_{m}\right)\right], m=$ $1,2,3, \ldots \ldots$, and here $k_{2}$ is:

$k_{2}=\frac{\pi^{2} D_{p i}}{4 l^{\prime} 2} f_{i 0} \int_{0}^{l} e^{-\frac{Z_{i} F \varphi(x)}{R T}} \mathrm{~d} x$

$N_{\infty}$ is:

$N_{\infty}=S f_{i 0} \int_{0}^{l} e^{-\frac{Z_{i} F \varphi(x)}{R T}} \mathrm{~d} x$

Equation 16 implies that, if the weak force adsorption is present, using experimental data to plot a relationship curve of $\left[N_{i}\left(t_{m+1}\right)-N_{i}\left(t_{m}\right)\right] / S\left(t_{m+1}-t_{m}\right)$ vs. $N_{i}\left(t_{m+1 / 2}\right)$, a straight line can be obtained, and the straight line bears three important characteristics: (1) the intercept of the straight line is the rate coefficient $k_{2}$ in the ion adsorption process; (2)the slope of the straight line is $\pi^{2} D_{p i} / 4 l^{2} S$; and (3) the total adsorption quantity $N_{\infty}$ at the equilibrium can be obtained directly by using the intercept and the slope values.

In summary, if a cation adsorption process in an experiment contains zero- and first-order kinetics, using experimental data to plot the relationship curves of $\left[N_{i}\left(t_{m+1}\right)-N_{i}\left(t_{m}\right)\right] / S\left(t_{m+1}-t_{m}\right)$ vs. $N_{i}\left(t_{m+1 / 2}\right)$, two straight lines could be obtained. In the initial stage of adsorption, the straight line will be parallel to the abscissa axis, and the intercept of the straight line will be the rate coefficient $k_{1}$; then, at a given time moment, that relationship curve will transfer to another straight line, the intercept and the slope of the straight line will be $k_{2}$ and $\pi^{2} D_{p i} / 4 l^{2} S$, respectively. The turning point of the two straight lines corresponds to the time when the strong force adsorption transfer to the weak force adsorption. Considering $l^{\prime}<l$, there must be $k_{2}>k_{1}$ (Comparing Eqs. 10 and 17). Thus, if both strong and weak forces adsorption presence, the two straight lines could be illustrate in Fig. 4.

When the Eqs. 12 and 16 were directly used to fit to the experimental kinetic data, the value of $N_{\infty}$ is not required in advance. In the past, it was common practice to use the

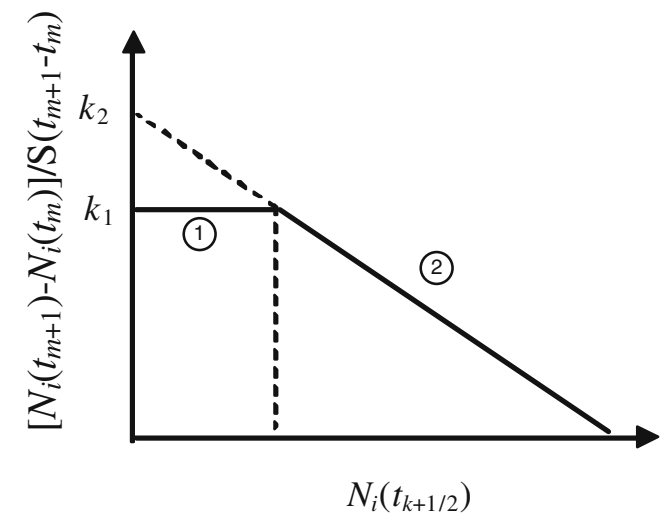

Fig. 4 The adsorption rate curves containing both strong and weak force adsorptions; (1) strong force adsorption, (2) weak force adsorption) 
integral form to describe the experiment data, and a straight line of $\ln \left(1-N_{i}(t) / N_{\infty}\right)$ vs. $t$ can be obtained when there exists the first-order process (Sparks and Jardine 1984; Aharoni et al. 1991; Jardine and Sparks 1984; Li and Xue 1996). But if the integral form is used, the $N_{\infty}$ value must be known in advance. Unfortunately, direct and accurate determination of the true $N_{\infty}$ is usually not possible. From theoretical analysis, the directly determined $N_{\infty}$ within a finite time will always be lower than the true value, because the true value can only be obtained when $t=\infty$.

When a lower than the true value of $N_{\infty}$ is used for describing the experimental data, the slope of the fitted curve of $\ln \left(1-N_{i}(t) / N_{\infty}\right)$ vs. $t$ will approach to infinite as time $t$ increases, similar to the dashed line shown in Fig. 5 . Considering the slope is the rate coefficient, $\pi^{2} D_{p i} / 4 l^{2} S$, if the obtained slope is infinite, this result must be absurd.

\section{Material and methods}

\subsection{Material and sample preparation}

The constantly charged material-montmorillonite was used as the experimental material. The montmorillonite was bought from Chi-Feng WHTB mining Co., Ltd., China. The surface properties of the montmorillonite determined by the method recently developed by $\mathrm{Li}$ et al. (unpublished material) are shown in Table 1 . The montmorillonite was pre- $\mathrm{H}^{+}$-saturated for the surface properties determination, and the method was based on the exchange equilibrium of $\mathrm{Na}^{+} / \mathrm{Ca}^{2+}$ at $\mathrm{pH}=7$ for the montmorillonite.

Theoretically speaking, the monovalent cations such as $\mathrm{K}^{+}$, $\mathrm{Na}^{+}$have weaker effect on shielding the negative electrostatic field from soil particle surface than that of the divalent cations such as $\mathrm{Ca}^{2+}, \mathrm{Mg}^{2+}$. Therefore, the electric field strength of the samples saturated with monovalent cations is much greater than that of the divalent cations saturated with the same electrolyte concentration. This implies that, as the negative charges on particle surface are saturated by $\mathrm{K}^{+}$, a

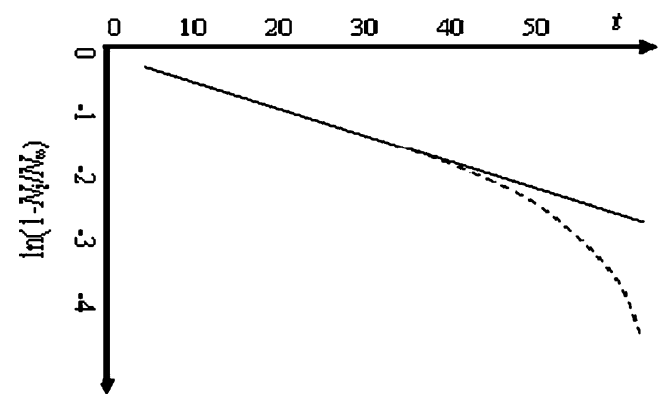

Fig. 5 The fitting result for the kinetic data as using the integral form of the first-order kinetic equation; solid line, as the adopted $N_{\infty}$ to be the true value, dotted line, as the adopted $N_{\infty}$ lower than the true value
Table 1 Determined surface properties of the montmorillonite

\begin{tabular}{llll}
\hline Sample & $\begin{array}{l}\text { Specific } \\
\text { surface area } \\
\left(S, \mathrm{~m}^{2} \mathrm{~g}^{-1}\right)\end{array}$ & $\begin{array}{l}\text { Surface charge } \\
\text { density } \\
\left(\sigma_{0}, \mathrm{mmol}_{(-)} \mathrm{m}^{-2}\right)\end{array}$ & $\begin{array}{l}\text { Surface charge } \\
\text { number } \\
\left(\mathrm{cmol}_{(-)} \mathrm{kg}^{-1}\right)\end{array}$ \\
\hline Montmorillonite & 650.5 & $9.562 \times 10^{-4}$ & 62.2 \\
\hline
\end{tabular}

stronger electrostatic field is potentially created, and thus a stronger force adsorption may exist for $\mathrm{Mg}^{2+}$ adsorption in the $\mathrm{Mg}^{2+} / \mathrm{K}^{+}$exchange experiment. On the other hand, as the negative charges on the particle surface are saturated by $\mathrm{Ca}^{2+}$, no strong electrostatic field will be created, and no strong force adsorption will exist for $\mathrm{Mg}^{2+}$ adsorption in the $\mathrm{Mg}^{2+}$ / $\mathrm{Ca}^{2+}$ exchange experiment. Therefore, in the experiment the samples were pre-saturated by $\mathrm{K}^{+}$and $\mathrm{Ca}^{2+}$, respectively, and the exchange cation was selected $\mathrm{Mg}^{2+}$.

\subsection{Kinetic studies of adsorption}

The kinetics of $\mathrm{Mg}^{2+}\left(\mathrm{Mg}\left(\mathrm{NO}_{3}\right)_{2}\right)$ adsorption in the $\mathrm{K}^{+}$- and $\mathrm{Ca}^{2+}$-saturated montmorillonites $\left(\mathrm{Mg}^{2+} / \mathrm{K}^{+}\right.$and $\mathrm{Mg}^{2+} / \mathrm{Ca}^{2+}$ exchange) were investigated by the miscible displacement under a steady flow condition. The experiment was carried out as follows: approximately $0.5 \mathrm{~g}$ of $\mathrm{K}^{+}$- or $\mathrm{Ca}^{2+}$-saturated montmorillonite was layered on an exchange column (the mass of the samples were determined at the end of each experiment finished). The thickness of the sample layer was very thin in the sample chamber for the purpose of reducing the effect of longitudinal concentration gradient in the experiment, since our theoretical analysis is based on the one-dimensional case. In our experiments, the sample layers were in the $0.2-0.3 \mathrm{~mm}$ range ( $\mathrm{Li}$ et al. 2010). The sample cross-sectional area was about $15 \mathrm{~cm}^{2}$. The experimental temperature was $298 \mathrm{~K}$. The concentration of $\mathrm{Mg}^{2+}$ in the flowing liquid was $10^{-4} \mathrm{molL}^{-1}$. The flow velocity of the solutions was $1.0 \mathrm{mlmin}^{-1}$. Effluent was collected at 10 -min intervals. The quantity of the ion that flowed through the interface $x=l$ into the fixed liquid film at $x=0 \rightarrow l$ for a period of time $t=0 \sim t$ was calculated based on the difference of $\mathrm{Mg}^{2+}$ concentration in the influent and the effluent.

\section{Results and discussion}

4.1 $\mathrm{Mg}^{2+}$ adsorption kinetic analyses for $\mathrm{Mg}^{2+} / \mathrm{K}^{+}$ and $\mathrm{Mg}^{2+} / \mathrm{Ca}^{2+}$ exchange

The experimental results of $\left[N_{i}\left(t_{m+1}\right)-N_{i}\left(t_{m}\right)\right] / S\left(t_{m+1}-t_{m}\right)$ vs. $N_{i}\left(t_{m+1 / 2}\right)$ for $\mathrm{Mg}^{2+}$ adsorption in $\mathrm{Mg}^{2+} / \mathrm{K}^{+}$and $\mathrm{Mg}^{2+} / \mathrm{Ca}^{2+}$ exchanges are shown in Figs. 6 and 7, respectively.

Figure 6 shows that: (1) The zero-order kinetic process was present in the initial stage of adsorption for $t=0-405 \mathrm{~min}$, which is an indication of strong force 


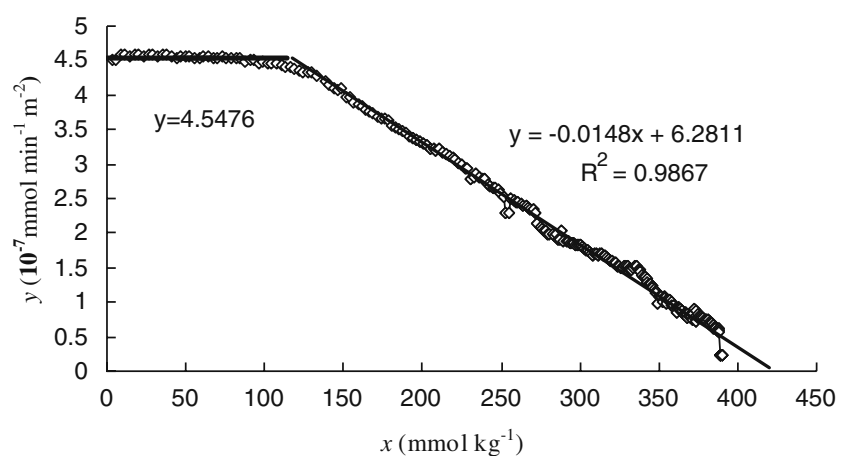

Fig. 6 The experimental results of the relationship between $y=$ $\left[N_{i}\left(t_{m+1}\right)-N_{i}\left(t_{m}\right)\right] / \mathrm{S}\left(t_{m+1}-t_{m}\right)$ and $x=N_{i}\left(t_{m+1 / 2}\right)$ of $\mathrm{Mg}^{2+}$ adsorption for $\mathrm{Mg}^{2+} / \mathrm{K}^{+}$exchange; empty diamonds, experimental data; solid line, fitting line

adsorption for $\mathrm{Mg}^{2+}$ in the experiment of $\mathrm{Mg}^{2+} / \mathrm{K}^{+}$ exchange. Since there exists no strong chemical bond between $\mathrm{Mg}^{2+}$ and the particle surface for the sample, the strong force adsorption can be attribute to the electrostatic force; and (2) The experimental results shown in Fig. 6 agree well with the theoretical prediction (see Fig. 4). After a period of time (about $405 \mathrm{~min}$ ) in the experiment, the adsorption process shifted to the first-order kinetic process, and the turning point from the zero-order to the first-order was very distinct.

However, for the $\mathrm{Mg}^{2+}$ adsorption in the $\mathrm{Mg}^{2+} / \mathrm{Ca}^{2+}$ exchange, the zero-order kinetic process did not appeared with the theoretical prediction (see Fig. 7). Therefore, for $\mathrm{Mg}^{2+}$ adsorption in $\mathrm{Mg}^{2+} / \mathrm{Ca}^{2+}$ exchange, only the weak force adsorption process was present.

It is well known that the electrostatic field strength around a particle in solution for $\mathrm{Ca}^{2+}$-saturated sample will be much weaker than that for the $\mathrm{K}^{+}$-saturate sample. Using the data shown in Table 1, the distribution of the potential energy $E(x)=Z F \varphi(x)$ of $\mathrm{Mg}^{2+}$ in the space adjacent particle surface was calculated ( $\mathrm{Li}$ et al. 2004). Figure 8 shows the distributions of the potential energy of $\mathrm{Mg}^{2+}$ in the space

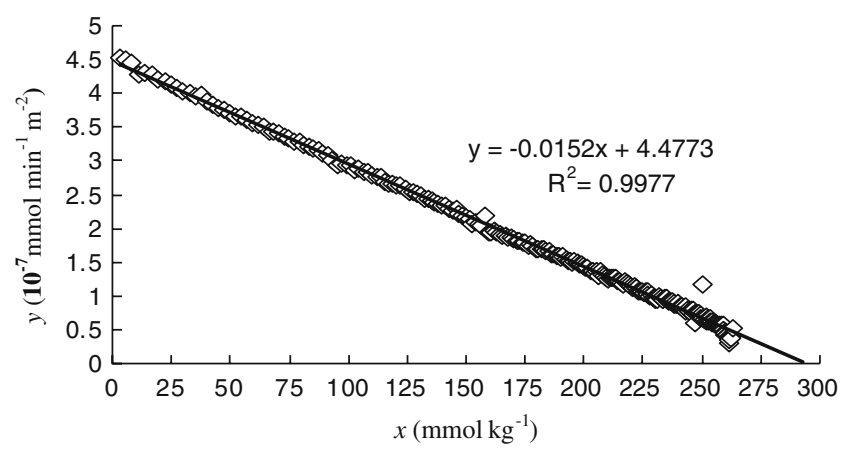

Fig. 7 The experimental results of the relationship between $y=$ $\left[N_{i}\left(t_{m+1}\right)-N_{i}\left(t_{m}\right)\right] / \mathrm{S}\left(t_{m+1}-t_{m}\right)$ and $x=N_{i}\left(t_{m+1 / 2}\right)$ of $\mathrm{Mg}^{2+}$ adsorption for $\mathrm{Mg}^{2+} / \mathrm{Ca}^{2+}$ exchange; empty diamonds, experimental data; solid line, fitting line adjacent to the particle surface for $\mathrm{Ca}^{2+}$ - and $\mathrm{K}^{+}$-saturated montmorillonites, respectively. In the calculation, we used the initial concentration in bulk solution of $10^{-5} \mathrm{molL}^{-1}$ for $\mathrm{Ca}^{2+}$ and $\mathrm{K}^{+}$in the suspensions of $\mathrm{Ca}^{2+}$ - and $\mathrm{K}^{+}$-saturated montmorillonites. We know that, in the preparation of a basic cation species saturated sample, the concentration of the basic cation species in bulk solution cannot much lower than $10^{-5} \mathrm{molL}^{-1}$. If the concentration is much lower than $10^{-5} \mathrm{~mol} / \mathrm{l}$, the adsorption quantity of $\mathrm{H}^{+}$on particle surface cannot be neglected because of $\mathrm{H}^{+} / \mathrm{K}^{+}$or $\mathrm{H}^{+} / \mathrm{Ca}^{2+}$ exchange even at $\mathrm{pH}=7$.

Figure 8 indicates that, at a given position in the space adjacent to particle surface, the potential energy of $\mathrm{Mg}^{2+}$ saturated in the $\mathrm{K}^{+}$-saturated sample is much lower than that in the $\mathrm{Ca}^{2+}$-saturated sample. For example, at a distance of $1 \mathrm{~nm}$ away from particle surface, the potential energy of adsorbed $\mathrm{Mg}^{2+}$ is $E_{\mathrm{Mg}}=-48,803 \mathrm{Jmol}^{-1}$ for the $\mathrm{K}^{+}$-saturated sample; while it is $E_{\mathrm{Mg}}=-21,806 \mathrm{Jmol}^{-1}$ for the $\mathrm{Ca}^{2+}$. saturated sample. Therefore, $\mathrm{Mg}^{2+}$ can be adsorbed much stronger in the $\mathrm{K}^{+}$-saturated montmorillonite than that in the $\mathrm{Ca}^{2+}$-saturated montmorillonite. On the other hand, at a distance of $1 \mathrm{~nm}$ away from particle surface, the difference of potential energy between $E_{\mathrm{Mg}}$ and $E_{\mathrm{Ca}}$ is $\Delta E_{\mathrm{Mg} / \mathrm{Ca}}=$ $E_{\mathrm{Mg}}-E_{\mathrm{Ca}}=-21,806+21,806=0 \mathrm{~J} \mathrm{~mol}^{-1}$ for the $\mathrm{Mg} / \mathrm{Ca}$ exchange; while the difference of potential energy between $E_{\mathrm{Mg}}$ and $E_{\mathrm{K}}$ was $\Delta E_{\mathrm{Mg} / \mathrm{K}}=E_{\mathrm{Mg}}-E_{\mathrm{K}}=$ $-48,803+48,803 / 2=-24,401.5 \mathrm{~J} \mathrm{~mol}^{-1}$ for the $\mathrm{Mg} / \mathrm{K}$ exchange, which indicates that the $\mathrm{Mg}^{2+}$ exchange for $\mathrm{K}^{+}$is much easier than $\mathrm{Mg}^{2+}$ exchange for $\mathrm{Ca}^{2+}$. Therefore, the $\mathrm{Mg} / \mathrm{K}$ exchange exhibits the zero-order kinetic process, while the $\mathrm{Mg} / \mathrm{Ca}$ exchange does not.

4.2 Estimation of dynamic and thermodynamic parameters in cation exchange

Because each parameter in the new kinetic equations has its definite physical meaning, some important dynamic and

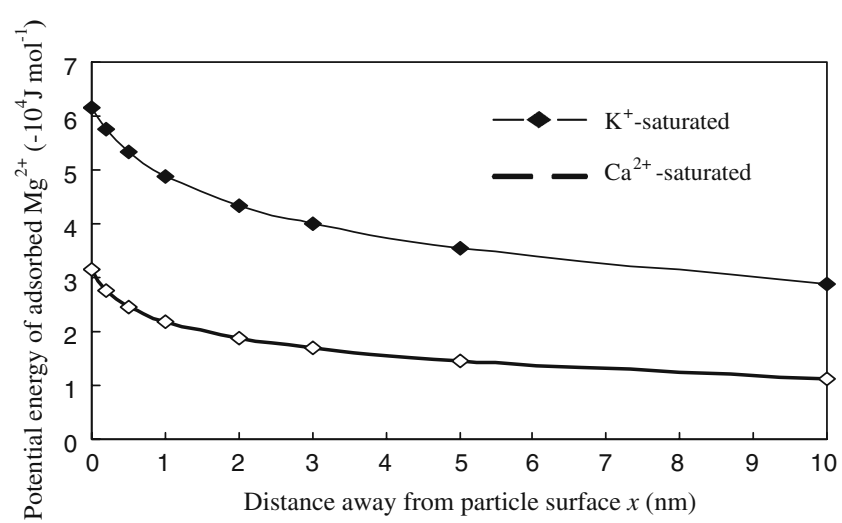

Fig. 8 The distributions of the potential energy of $\mathrm{Mg}^{2+}$ in the space adjacent montmorillonite particle surface for the $\mathrm{Ca}^{2+}$ - and $\mathrm{K}^{+}$saturated samples, respectively 
thermodynamic parameters in cation exchange can be calculated based on the new theory for describing the cation adsorption.

(1). Estimation of the adsorbed quantities of $\mathrm{Mg}^{2+}$ by the strong and weak force adsorption at equilibrium

From Eq. 16, using the slope and the intercept of the straight line shown in Figs. 6 or 7, the total adsorbed quantities: $N_{\infty}$ can be calculated as:

$N_{\infty}=\frac{k_{2}}{\mid \text { slop } \mid}$

Since both strong and weak force adsorptions coexisted for the $\mathrm{Mg}^{2+}$ adsorption in the $\mathrm{Mg} / \mathrm{K}$ exchange, from Fig. 6 the calculated $k_{2}=6.2811 \times$ $10^{-7} \mathrm{mmolmin}^{-1} \mathrm{~m}^{-2}$, and $\mid$ slope $\mid=0.0148 \times$ $10^{-7} \mathrm{~kg} \mathrm{~min}^{-1} \mathrm{~m}^{-2}$. Using the two values, in Eq. 19, the calculated the total adsorbed quantities: $N_{\infty}=424.4 \mathrm{mmol} \mathrm{kg}^{-1}$. The adsorption quantity of $\mathrm{Mg}^{2+}$ at the turning point represents the maximum quantity of the strong force adsorption at equilibrium, while the difference between the total adsorption and the adsorption at the turning point is the weak force adsorption (see Fig. 6). According to the fitting equations shown in Fig. 6, at the turning point we had:

$4.5476=-0.0148 x+6.2811$

where $x$ is the adsorption quantity of $\mathrm{Mg}^{2+}$ at the turning point.

From Eq. 20 we can get the quantity of the strong force adsorption of $\mathrm{Mg}^{2+}$ at equilibrium, it was $117.1 \mathrm{mmolkg}^{-1}$. We can further calculate the quantity of the weak force adsorption of $\mathrm{Mg}^{2+}$ at equilibrium, it was $424.4-117.1=307.3 \mathrm{mmolkg}^{-1}$. Considering the electro-neutrality principle, for a constantly charged material-montmorillonite, the total surface charge or the surface charge at the origin of the strong force adsorption layer is $424.4 \times 2 \mathrm{mmol}_{(-)} \mathrm{kg}^{-1}=84.9$ $\mathrm{cmol}_{(-)} \mathrm{kg}^{-1}$. Correspondingly, the charge at the origin of the weak force layer is $307.3 \times 2 \mathrm{mmol}_{(-)} \mathrm{kg}^{-1}=61.5$ $\mathrm{cmol}_{(-)} \mathrm{kg}^{-1}$, which is very close to the determined surface charge number of $62.2 \mathrm{cmol}_{(-)} \mathrm{kg}^{-1}$, as shown in Table 1.

Considering $\mathrm{H}^{+}$has a stronger adsorption force in a given electrostatic field than $\mathrm{Ca}^{2+}$, this results might imply that, if a $\mathrm{H}^{+}$-saturated sample were used in the cation exchange experiment for surface properties determination, a portion of the strongly adsorbed $\mathrm{H}^{+}$ could not be exchanged by a basic cation species, e.g., $\mathrm{Ca}^{2+}$ and $\mathrm{Na}^{+}$there.

Since only the weak force adsorption exists for $\mathrm{Mg}^{2+}$ adsorption in the $\mathrm{Mg} / \mathrm{Ca}$ exchange, from Fig. 7 and Eq. 19, the calculated adsorption quantity of $\mathrm{Mg}^{2+}$ at equilibrium is $4.4773 / 0.0152=294.6 \mathrm{mmolkg}^{-1}$, which means that the surface charges at the origin of the weak force adsorption layer is $58.92 \mathrm{cmol}_{(-)} \mathrm{kg}^{-1}$. This result also indicates that, because $\mathrm{Ca}^{2+}$ has a stronger adsorption force in a given electrostatic field than $\mathrm{Mg}^{2+}$, a portion of the strongly adsorbed $\mathrm{Ca}^{2+}$ cannot be exchanged by $\mathrm{Mg}^{2+}$.

The above discussions shows that, either from the experiment of $\mathrm{Mg} / \mathrm{K}$ exchange, $\mathrm{Mg} / \mathrm{Ca}$ exchange, or $\mathrm{Ca} / \mathrm{H}$ and $\mathrm{Na} / \mathrm{H}$ exchange, the obtained surface charge numbers at the origin of the weak force adsorption layer are almost the same, they are 61.5, 58.9 and 62.2 $\mathrm{cmol}_{(-)} \mathrm{kg}^{-1}$, respectively. The results seemingly implied, only when the strong force adsorption exists for cation exchange, e.g., the $\mathrm{Mg} / \mathrm{K}$ exchange, the total surface charge number at the origin of the strong force adsorption layer can be obtained.

(2). Estimation of the thicknesses of the strong and weak force adsorption layers

Based on the new theory, the average thicknesses of the strong and weak force adsorption layers can be calculated. From Eqs. 11 and 17, we obtain:

$\frac{l^{\prime}}{l}=\sqrt{\frac{k_{1}}{k_{2}}}$

In this exchange experiment, the sample was almost water saturated, and the saturated water content in this experiment for the montmorillonite was $2.44 \mathrm{mlg}^{-1}$ approximately. Therefore the average thickness of the fixed liquid film was $l=2.44 \times$ $10^{-6}\left(\mathrm{~m}^{3} \mathrm{~g}^{-1}\right) / 650.5\left(\mathrm{~m}^{2} \mathrm{~g}^{-1}\right)=3.75 \mathrm{~nm}$.

From Fig. 6, we had $k_{1}=4.5476 \times 10^{-7} \mathrm{mmol}$ $\min ^{-1} \mathrm{~m}^{-2}, k^{2}=6.2811 \times 10^{-7} \mathrm{mmolmin}{ }^{-1} \mathrm{~m}^{-2}$, introducing them into Eq. 21 , we get $l^{\prime} / l=0.8509$. Therefore, the average thickness of the weak force adsorption layer was $l^{\prime}=0.8509 l=3.192 \mathrm{~nm}$, and the average thickness of the strong force adsorption layer was $0.1491 l=0.5591 \mathrm{~nm}$ in this experiment for the montmorillonite.

(3). Estimation of the apparent diffusion coefficient of cations

From Eqs. 17 and 18, we have:

$D_{p i}=\frac{4 S l^{\prime} 2}{\pi^{2}} \cdot \frac{k_{2}}{N_{\infty}}$

Introducing the corresponding values into Eq. 22, we get the apparent diffusion coefficient of $\mathrm{Mg}^{2+}$ in the montmorillonite: $D_{p i}=4 \times 650.5 \times$ $\left(3.192 \times 10^{-9}\right)^{2} \times 6.2811 \times 10^{-7} / 3.14^{2} \times 0.4244=$ $3.979 \times 10^{-21} \mathrm{~m}^{2} \mathrm{~min}^{-1}$.

(4). Estimation of the average activity coefficient of the adsorbed cations 
Low (1981) defined an average activity coefficient of electrostatic adsorbed ions:

$\widetilde{\gamma}_{i}=\frac{1}{\frac{1}{l} \int_{0}^{l} e^{-\frac{Z_{i} F \varphi(x)}{R T}} \mathrm{~d} x}$

where $\widetilde{\gamma}_{i}$ is the average activity coefficient for all the electrostatic adsorbed $\mathrm{Mg}^{2+}$. Combining Eqs. 18 and 23 gives:

$\widetilde{\gamma}_{i}=\frac{S l f_{i 0}}{N_{\infty}}$

Also, for the strong force adsorption ions, according to the definition of the average activity coefficient of adsorbed ions by $\mathrm{Li}$ and $\mathrm{Wu}(2007)$, there is:

$\widetilde{\gamma}_{i}(s)=\frac{f_{i 0}}{\widetilde{f}_{i}(s)}=\frac{f_{i 0}}{\frac{N_{i}(s)}{S\left(l-l^{\prime}\right)}}=\frac{S\left(l-l^{\prime}\right) f_{i 0}}{N_{i}(s)}$

for the weak force adsorption ions, there is:

$\widetilde{\gamma}_{i}(w)=\frac{f_{i 0}}{\widetilde{f}_{i}(w)}=\frac{f_{i 0}}{\frac{N_{i}(w)}{S l^{\prime}}}=\frac{S l f_{i 0}}{N_{i}(w)}$

where $\widetilde{\gamma}_{i}(s), \widetilde{\gamma}_{i}(w)$ is the average activity coefficient of the adsorbed $\mathrm{Mg}^{2+}$ for the strong and weak force adsorptions, respectively; $\widetilde{f}_{i}(s), \widetilde{f}_{i}(w)$ is the average concentration of the adsorbed $\mathrm{Mg}^{2+}$ at equilibrium for strong and weak force adsorptions, respectively; $N_{i}(s)$, $N_{i}(w)$ are the quantities of the adsorbed $\mathrm{Mg}^{2+}$ at equilibrium for strong and weak force adsorptions, respectively.

Based on the above obtained values of $N_{\infty}, N_{i}(s)$ and $N_{i}(w)$, the average activity coefficients of the total electrostatic adsorption $\mathrm{Mg}^{2+}$, the strong electrostatic force adsorption $\mathrm{Mg}^{2+}$, and the weak electrostatic force adsorption $\mathrm{Mg}^{2+}$ can be calculated, the results are listed in Table 2. The data in Table 2 show that: (1) the average activity coefficient of $\mathrm{Mg}^{2+}$ is far smaller than 1 due to the influence of the electrostatic field from surface charges of soil particles; (2) the average activity coefficient of $\mathrm{Mg}^{2+}$ for the strong electrostatic force adsorption is much lower than that for the weak electrostatic force adsorption; (3) for the $\mathrm{Mg} / \mathrm{Ca}$ exchange, all the adsorbed $\mathrm{Mg}^{2+}$ have high activity because only weak force adsorption exists.

The Debye characteristic length, $1 / \kappa$ was estimated to be $17.3 \mathrm{~nm}$ in this experiment, where $\kappa$ is the DebyeHuckel parameter. The above discussions showed that, the average thickness of liquid film in the montorillonite was merely $3.75 \mathrm{~nm}$ in the experiment, thus $l<<1 / \kappa$, which implies that the diffuse layer at the inner surface of the montmorillonite was not fully expanded.

Considering the electro-neutrality rule:

$S f_{i 0} \int_{0}^{\frac{1}{\kappa}} e^{-\frac{Z_{i} F \varphi(x)}{R T}} d x=S f_{i 0} \int_{0}^{l} e^{-\frac{Z_{i} F \varphi(x)}{R T}} \mathrm{~d} x$

thus as $l<1 / \kappa$, there will be:

$$
\begin{aligned}
\widetilde{\gamma}_{i}(l) & =l \cdot \frac{1}{\int_{0}^{l} e^{-\frac{z_{i} F \varphi(x)}{R T}} \mathrm{~d} x}<\widetilde{\gamma}_{i}(1 / \kappa) \\
& =\frac{1}{\kappa} \cdot \frac{1}{\int_{0}^{\frac{1}{\kappa}} e^{-\frac{z_{i} F \varphi(x)}{R T}} \mathrm{~d} x}
\end{aligned}
$$

Equation 28 shows that, as $l<1 / \kappa$, there must be $\tilde{\gamma}_{i}(l) \tilde{\gamma}_{i}(1 / \kappa)$. Therefore, under the same temperature and electrolyte conditions for the same sample, the activity of the adsorbed ions in a not fully expanded diffuse layer is much lower than that in a fully expanded diffuse layer.

\section{Conclusions}

By considering the electric field from particle surface, new exact kinetic equations for describing cation adsorption were developed. The new equations show that, when both strong force adsorption and weak force adsorption coexist in an exchange experiment, the initial stage of strong force

Table 2 The average activity coefficients of the adsorbed $\mathrm{Mg}^{2+}$

\begin{tabular}{lcccccc}
\hline Treatments & $N_{\infty}{ }^{\mathrm{a}}\left(\mathrm{mmolkg}^{-1}\right)$ & $N_{i}(s)^{\mathrm{b}}\left(\mathrm{mmolkg}^{-1}\right)$ & $N_{i}(w)^{\mathrm{c}}\left(\mathrm{mmolkg}^{-1}\right)$ & $\tilde{\gamma}(s) \times 10^{-4} d$ & $\tilde{\gamma}(w) \times 10^{-4} e$ & $\tilde{\gamma} \times 10^{-4} f$ \\
\hline $\mathrm{Mg} / \mathrm{K}$ exchange & 424.4 & 117.1 & 307.3 & 3.106 & 6.756 & 5.755 \\
$\mathrm{Mg} / \mathrm{Ca}$ exchange & 294.6 & 0 & 294.6 & $\sim$ & 7.047 & $\sim$ \\
\hline
\end{tabular}

${ }^{\mathrm{a}}$ Totally adsorbed quantities of $\mathrm{Mg}^{2+}$ at equilibrium

${ }^{\mathrm{b}}$ Strong force adsorption quantities of $\mathrm{Mg}^{2+}$ at equilibrium

${ }^{\mathrm{c}}$ Weak force adsorption quantities of $\mathrm{Mg}^{2+}$ at equilibrium

${ }^{\mathrm{d}}$ Average activity coefficient of the strong force adsorption $\mathrm{Mg}^{2+}$

${ }^{\mathrm{e}}$ Average activity coefficient of the weak force adsorption $\mathrm{Mg}^{2+}$

${ }^{\mathrm{f}}$ Average activity coefficient for the whole adsorbed $\mathrm{Mg}^{2+}$ 
adsorption can be described by the zero-order kinetics. The adsorption then shifts to the first-order kinetics of the weak force adsorption. In this study, $\mathrm{K}^{+}$- and $\mathrm{Ca}^{2+}$-saturated montmorillonites were used in the $\mathrm{Mg}^{2+} / \mathrm{K}^{+}$and $\mathrm{Mg}^{2+} / \mathrm{Ca}^{2+}$ exchange to verify the theory. As predicted, because $\mathrm{K}^{+}$saturated montmorillonite can form a much stronger electrostatic field adjacent to the particle surface than the $\mathrm{Ca}^{2+}$ saturated montmorillonite, $\mathrm{Mg}^{2+}$ adsorption in $\mathrm{K}^{+}$-saturated sample appeared to be a zero-order kinetic process in the initial stage ( $t=0-405 \mathrm{~min})$ of the strong force adsorption; the adsorption process then shifted to the first-order kinetics of the weak force adsorption. However, for the $\mathrm{Ca}^{2+}$-saturated sample, only the first-order kinetic process was observed for $\mathrm{Mg}^{2+}$ adsorption, because only weak electrostatic field presents in the system. Either for $\mathrm{Mg}^{2+} / \mathrm{K}^{+}$exchange or $\mathrm{Mg}^{2+} / \mathrm{Ca}^{2+}$ exchange, the quantities of $\mathrm{Mg}^{2+}$ weak force adsorption at equilibrium were approximately the same (307.3 and $294.6 \mathrm{mmolkg}^{-1}$, respectively).

The new kinetic equations are mathematically precise, and they were derived from the actual physical mechanism of cation adsorption. Thus, those new equations are fundamentally different from the classic apparent kinetic equations. All the parameters in the new equations have definite physical significance. Therefore, using the new equations, some important dynamic and thermodynamic parameters in cation exchange can be estimated from the experimental data. These parameters include the total adsorption quantity, the strong force adsorption quantity and the weak force adsorption quantity of cation at equilibrium; the thicknesses of the strong force adsorption layer and the weak force adsorption layer; the apparent diffusion coefficient of cation in clay; and the average activity coefficients of the adsorbed cations for the strong and weak force adsorptions.

The study also indicates that, only when the strong force adsorption exists for cation exchange, e.g., the $\mathrm{Mg} / \mathrm{K}$ exchange, the total surface charge number at the origin of the strong force adsorption layer can be determined through the cation exchange method.

\section{Recommendations and perspectives}

The new theory unifies the diffusion process of cations in solution, the diffusion process of cations in diffuse layer, and the exchange process of cations on surface, which opens a new window for future research of investigating the chemical adsorption mechanisms of heavy metal ions on particle surface. Currently, for heavy metal ions adsorption, only an overall process containing all types of diffusion processes, physical adsorption process and chemical adsorption process, can be detected in experiment.

Acknowledgements This work was supported by the National Natural Science Foundation of China (Grant No. 40671090 and 40740420660) and the National Basic Research Program of China (Grant No. 2010CB134511).

Open Access This article is distributed under the terms of the Creative Commons Attribution Noncommercial License which permits any noncommercial use, distribution, and reproduction in any medium, provided the original author(s) and source are credited.

\section{References}

Aharoni C, Sparks DL, Levinson S, Ravina I (1991) Kinetics of soil chemical reactions: relationships between empirical equations and diffusion models. Soil Sci Soc Am J 55:1307-1312

Jardine PM, Sparks DL (1984) Potassium-calcium exchange in a multireactive soil system: I. kinetics. Soil Sci Soc Am J 48:29-45

Kemper WD, Van Schaik JC (1966) Diffusion of salts in clay-water systems. Soil Sci Soc Am Proc 30:534-540

Li H, Xue JH (1996) Study on ion diffusion kinetics in soil systems. Acta Pedologica Sinica 33(4):327-336, in Chinese

Li H, Wu LS (2004) On the relationship between thermal diffusion and molecular interaction energy in binary mixtures. J Phys Chem B 108:13821-13826

Li H, Wu LS (2007) A new approach to estimate ion distribution between the exchanger and solution phases. Soil Sci Soc Am J $71: 1694-1698$

Li R, Li H (2010) Comparison between $\mathrm{Mg}^{2+}-\mathrm{K}^{+}$and $\mathrm{Ca}^{2+}-\mathrm{K}^{+}$ exchange kinetics as considering the electric fields at solid-liquid interface of soil. Acta Phys Chim Sin 26:552-560

Li H, Qing CL, Wei SQ, Jiang XJ (2004) An approach to the method for determination of surface potential on solid/liquid interface: theory. J Colloid Interf Sci 275:172-176

Li H, Li R, Zhu HL, Wu LS (2010) The influence of electrostatic field from soil particle surfaces on ion adsorption/diffusion. Soil Sci Soc Am J 74(4):1129-1138

Low PF (1981) Soil physical chemistry. Agricultural, Beijing (in Chinese)

Sparks DL, Jardine PM (1984) Comparison of kinetics equations to describe K-Ca exchange in pure and in mixed systems. Soil Sci 138:115-122 